\title{
Multiband Printed Loop Mobile Phone Antenna for LTE/WWAN/GNSS Application
}

\author{
Yuan Xu and Hao-Miao Zhou \\ College of Information Engineering, China Jiliang University, Hangzhou 310018, China \\ Correspondence should be addressed to Hao-Miao Zhou; zhouhm@cjlu.edu.cn
}

Received 12 November 2015; Accepted 28 January 2016

Academic Editor: Ahmed A. Kishk

Copyright (C) 2016 Y. Xu and H.-M. Zhou. This is an open access article distributed under the Creative Commons Attribution License, which permits unrestricted use, distribution, and reproduction in any medium, provided the original work is properly cited.

A multiband printed loop mobile phone antenna for LTE/WWAN/GNSS application is presented. It covers seven communication bands (VSWR < 3) and GNSS band (VSWR < 1.5). The so-called GNSS (global navigation satellite system) band includes COMPASS, GALILEO, GPS, and GLONASS. From the analysis of the structure, the coupled-fed antenna mainly consists of three parts: the feeding strip, shorted strip, and U-shaped parasitic coupling strip. The proposed antenna works in three resonant modes, respectively, at $860 \mathrm{MHz}(0.25 \lambda), 1620 \mathrm{MHz}(0.5 \lambda)$, and $2620 \mathrm{MHz}(1 \lambda)$. A solution is provided, by which the navigation antenna can be integrated into the communication main antenna to save space. The antenna not only can work in GSM850/900/1800/1900/UMTS2100/LTE2300/2500 bands but also covers the world's four major navigation systems. Moreover, the proposed antenna can be easily printed on the circuit board without loading any lumped element and only occupies a small volume of $18 \times 32 \times 3 \mathrm{~mm}^{3}$, which is suitable for smartphone application. In addition, the redundant design of multinavigation system is quite favorable for the elimination of errors or shadow area caused by single navigation system, especially for outdoor investigation, national security, and so on.

\section{Introduction}

Mobile technology has been developed rapidly. From the 1980 s, these technologies successively appeared, such as the first-generation analog voice system, the second-generation narrowband digital voice system, and the third- and fourthgeneration mobile communication (3G, 4G). The fifthgeneration mobile communications (5G) will also appear in the future. The common $2 \mathrm{G} / 3 \mathrm{G} / 4 \mathrm{G}$ bands are GSM850 (824-894 MHz), GSM900 (890-960 MHz), GSM1800 (1710$1880 \mathrm{MHz})$, GSM1900 (1850-1990 MHz), UMTS2100 (1920$2170 \mathrm{MHz}$ ), LTE2300 (2305-2400 MHz), and LTE2500 (2500$2690 \mathrm{MHz}$ ). In a limited area, the design concept of phone antenna is the realization of multiband coverage through excellent design and proper impedance matching. Meanwhile, for the current market of smartphone, navigation and positioning functions become indispensable. A navigation antenna is especially provided for most phones, which mainly covers GPS band (Global Positioning System, US $1575.42 \pm$ $5 \mathrm{MHz}$ ). In addition, three of global navigation systems such as Chinese COMPASS (1559.052-1591.788 MHz), the European Galileo (1563-1591 MHz), and the Russian GLONASS $(1602-1615.5 \mathrm{MHz})$ are also booming [1]. However, a single navigation system may bring some errors or blind spots. A lot of mobile phones require a navigation antenna to cover band of multiple navigation systems. The navigation signal directly from the satellite is much weaker than the communication signal from the base station. So the requirement of the band covering is stricter, and the VSWR is less than $1.5: 1$ in general. At present, mobile phone with four global navigation systems is rare. And an antenna covering seven communication bands with four navigation systems is more uncommon. Therefore, the design of mobile phone antenna will be faced with great challenges.

In recent years, in order to meet the requirements of current mobile phone built-in antenna, monopole antenna [2-4], PIFA antenna [5, 6], and many other types of antennas have been designed. Loop antenna with unique multimode feature was mentioned in [7], which can provide a viable solution for the application of multibands mobile phone 
antenna. However, for loop antenna with high resonant impedance characteristics [8], it is difficult that the loop antenna with good impedance matching is designed in a small space. Various tuning techniques also have been studied and applied. The resonance impedance of the antenna can be improved by increasing the tuning patch, but the $0.25 \lambda$ resonance mode cannot be generated and the volume of the antenna was larger in [9]. A reconfigurable technology was used in [8], which is using a diode or a match bridge in the current density areas to control the current direction, and thereby the resonance characteristic of the loop antenna was controlled. But the structure of the loop antenna was too complicated. Chi and Wong $[10,11]$ used the coupled feeding ways to improve the antenna resonance impedance; namely, the feeding monopole antenna was used to excite loop antenna through electromagnetic coupling. Then, in [11], the $0.25 \lambda$ resonant mode, which is not excited by the usual loop antenna, was excited, but the antenna only covered the WWAN band.

A multiband printed loop mobile phone antenna for LTE/WWAN/GNSS application is presented. A solution is provided, by which the navigation antenna can be integrated into the communication main antenna to save space. This antenna covers two bands for the $821 \mathrm{MHz}-1012 \mathrm{MHz}$ and $1375 \mathrm{MHz}-2937 \mathrm{MHz}$, and the integrated bandwidth between the $0.5 \mathrm{GHz}$ and the $3 \mathrm{GHz}$ is up to $1753 \mathrm{MHz}$. The antenna not only can work in GSM850/900/1800/1900/UMTS2100/ LTE2300/2500 bands but also covers the world's four major navigation systems. The coupled-fed antenna works in three resonance modes, respectively, which includes $860 \mathrm{MHz}$ $(0.25 \lambda), 1620 \mathrm{MHz}(0.5 \lambda)$, and $2620 \mathrm{MHz}(1 \lambda)$. Therefore, the proposed antenna is easily printed on the circuit board without loading any lumped element and only occupies a small volume of $18 \times 32 \times 3 \mathrm{~mm}^{3}$, which achieves the multibands and miniaturization. The structure and the test results of the antenna are discussed in detail.

\section{Antenna Configuration and Design}

Figure 1 is the overall geometry structure of antenna and shows the detailed dimension parameters of the antenna. The antenna has been processed and measured and the front and back photos of the fabricated antenna are shown in Figure 2. The proposed antenna is directly printed on a $0.8 \mathrm{~mm}$ thick FR4 substrate with the area of $60 \times 115 \mathrm{~mm}^{2}$, where relative permittivity of substrate is 4.4 and loss tangent of substrate is 0.02 . The proposed antenna is located in the bottom edge of the system circuit board and only occupies a small volume of $18 \times 32 \times 3 \mathrm{~mm}^{3}$. One end-portion (point A) of the feeding strip, which is the feeding point of the proposed antenna, is connected with the coaxial feed line with characteristic impedance of $50 \Omega$. The end-portion (point B) of the shorted strip is directly connected with the main ground plane through a via-hole in the system circuit board.

The antenna consists of three parts: feeding strip AC, shorted strip BF, and U-shaped coupling parasitic strip DE. The feeding strip directly feeds and covers the high band. The feeding strip and shorted strip are with vertical metal sheet in order to save the base board area by the use of the space. And the shorted strip with coupling feed covers lower band and has wind distributed inductance for adjusting the impedance matching. The U-shaped parasitic coupling strip is completely unconnected with the other two parts and the ground plane, which is totally dependent on the coupling effect. Moreover, it is equivalent to the capacitor connected to the antenna. On one hand, it can adjust the resonant frequency of antenna; on the other hand, a high quality resonant mode (VSWR < 1.5) is produced at $1620 \mathrm{MHz}$, which is used to cover GNSS band.

Typically, loop antenna can work in $2 \times 1 / 4 \lambda(0.5 \lambda)$ and $2 \times 3 / 4 \lambda(1.5 \lambda)$ two unbalanced modes as folded monopole antenna and can work in $2 \times 1 / 2 \lambda(1 \lambda)$ balance mode as folded dipole antenna, and the loop antenna also can motivate the resonant $2 \lambda$ mode through appropriate tuning techniques. The feature of multiresonant mode makes the loop antenna cover multiband mobile communications systems more easily. However, it means that the length of the loop antenna will be 0.5 times as much as the wavelength of the lower frequency, such as [7].

The innovation in the structure of the proposed antenna is covering so many bands and stimulating the $0.25 \lambda$ mode at the same time. This is due to the unique structure of the antenna, which is considered as a chopped loop antenna, so it has parts of features which existed in loop antenna and PIFA antenna. If the gap (between the F and $\mathrm{C}$ ) is regarded as a capacitor, it is a lumped capacitance connecting loop antenna. Viewed from another angle, it is also a PIFA-like antenna objectively, so it has $0.25 \lambda$ mode. Making the length of the loop antenna requires only 0.25 times as much as the wavelength of the lower band, which is very beneficial for the miniaturization of antennas. Compared with the volume of $50 \times 13 \times 5 \mathrm{~mm}^{3}\left(3250 \mathrm{~mm}^{3}\right)$ of the loop antenna given by [7], the volume of the proposed antenna is only $32 \times$ $18 \times 3 \mathrm{~mm}^{3}\left(1728 \mathrm{~mm}^{3}\right)$. And the proposed antenna covers more bands-LTE2300 (2305-2400 MHz), LTE2500 (2500$2690 \mathrm{MHz})$, and GNSS (1559-1615 MHz) bands.

In general, the parasitic strip is shorted to ground, and the RF signal is coupled through the slot from the feeding strip to the parasitic strip, so that the low frequency impedance is relatively flat and a wider impedance matching in upper bands is achieved. So the antenna can work in multifrequency mode. However, in this antenna design, through simulation, it has been found that parasitic unit is designed to be $\mathrm{U}$ shaped and breaking the contact with the shorted strip will be better for this particular antenna. And the simulation result has been confirmed by experiment.

\section{Experiment Results and Discussion}

Figure 3 shows the measured and simulated return loss of the antenna. The measured results are obtained by a vector network analyzer (Agilent N5230C). As shown in Figure 3, the measured data are consistent with the simulated value and three resonant modes are generated at $860 \mathrm{MHz}, 1620 \mathrm{MHz}$, and $2620 \mathrm{MHz}$, respectively. In the standard of $\operatorname{VSWR}<3: 1$, this antenna covers $821 \mathrm{MHz}-1012 \mathrm{MHz}$ band and $1375 \mathrm{MHz}-$ $2937 \mathrm{MHz}$ band, and the integrated bandwidth between $0.5 \mathrm{GHz}$ and $3 \mathrm{GHz}$ is up to $1753 \mathrm{MHz}$. 


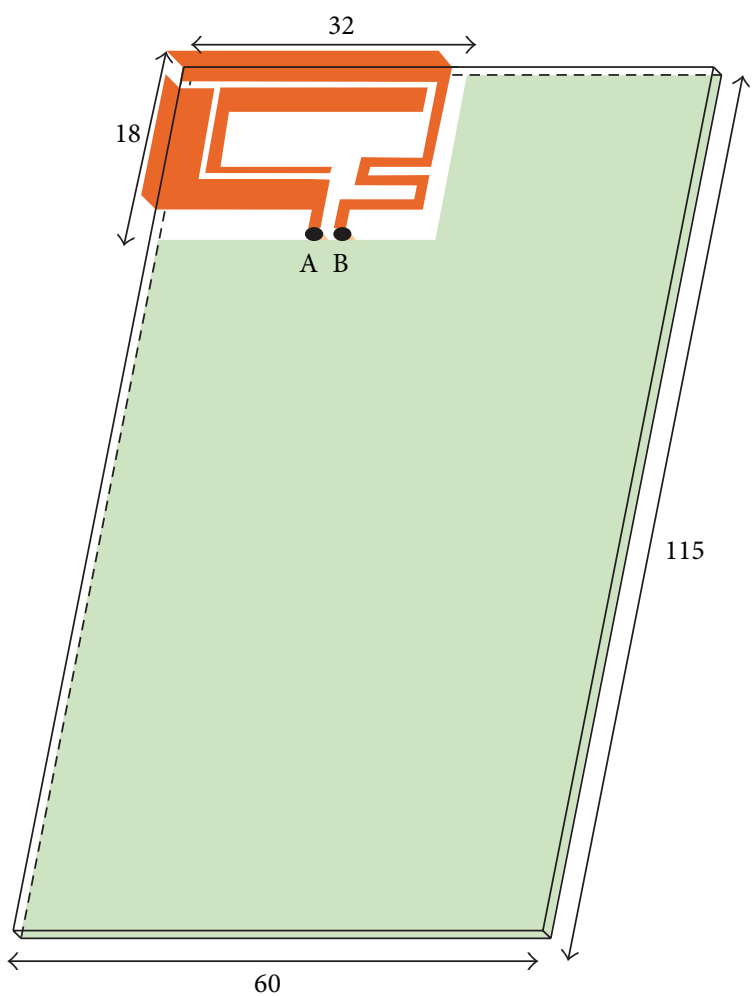

A: feeding point

B: grounding point

(a)

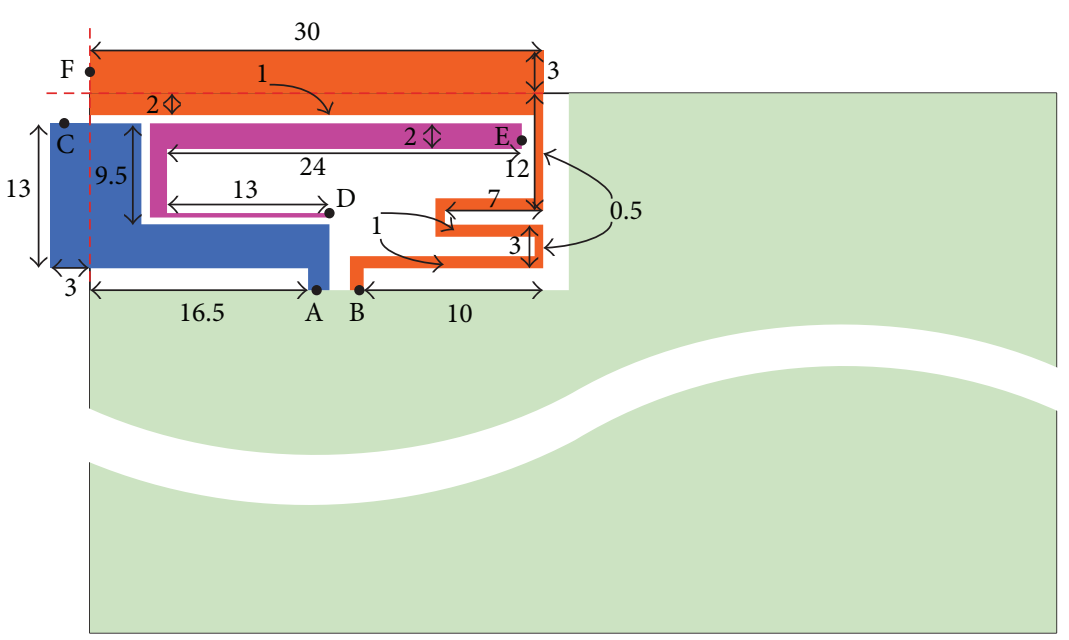

(b)

Figure 1: (a) Geometry of the proposed antenna. (b) Dimensions of the metal pattern of the antenna (unit: millimeters).

Since the satellite signal is weak, GNSS band needs to be covered in a higher standard. Usually in the standard of VSWR $<1.5: 1(-14 \mathrm{~dB})$, the band is $1534 \mathrm{MHz}-1668 \mathrm{MHz}$ in the vicinity of GNSS band, which fully covers the four navigation system bands.

In order to analyze the structure of the antenna, Figure 4 shows the comparison between the simulated reflection coefficient and reflection coefficient of referenced antenna
(Ref 1 contains feeding strip AC; Ref 2 contains feeding strip $\mathrm{AC}$ and shorted strip BF; Ref 3 contains feeding strip AC and U-shaped coupling parasitic strip DE). The high band of Ref 1 antenna is quite wide but cannot be completely covered. Ref 3 antenna with U-shaped coupling parasitic strip can cover the entire high band, but it does not have a lower frequency resonant mode. Ref 2 antenna, the combination of feeding strip $\mathrm{AC}$ and shorted strip BF, can generate low frequency and high 


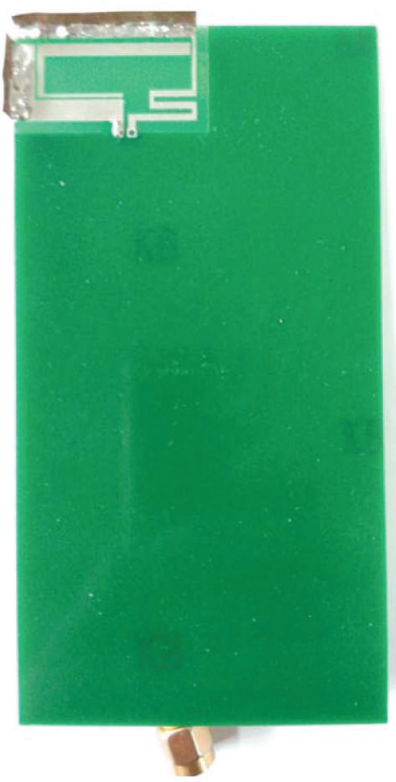

(a)

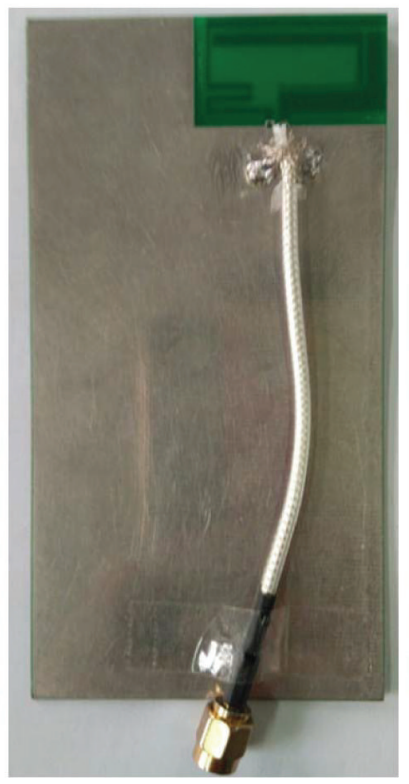

(b)

FIGURE 2: Photograph of the manufactured printed antenna. (a) Front view; (b) back view.

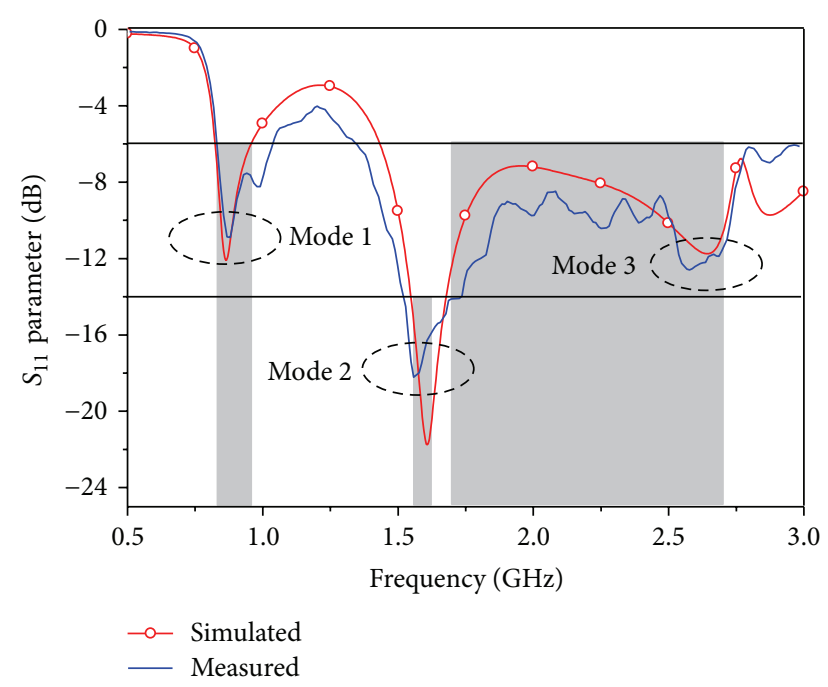

FIGURE 3: The measured and simulated return loss of the antenna.

frequency resonant modes but cannot cover the target bands. The antenna which contains U-shaped coupling parasitic strip DE besides the above three parts can cover target bands.

The antenna used the close-coupled feeding, and the feeding strip is close to but not connected with the shorted strip, to realize power coupling through electromagnetic effect. The key feature of close-coupled feed is that it is essentially capacitive coupling mechanism, and direct contact method is mainly inductive. This difference makes closecoupled feed method able to obtain a wider impedance bandwidth. The coupling (interaction) between the feeding strip AC and shorted strip BF can obtain the most optimal impedance bandwidth by adjusting the distance. Considering the distance $d$ between the feed point $\mathrm{A}$ and the shorted

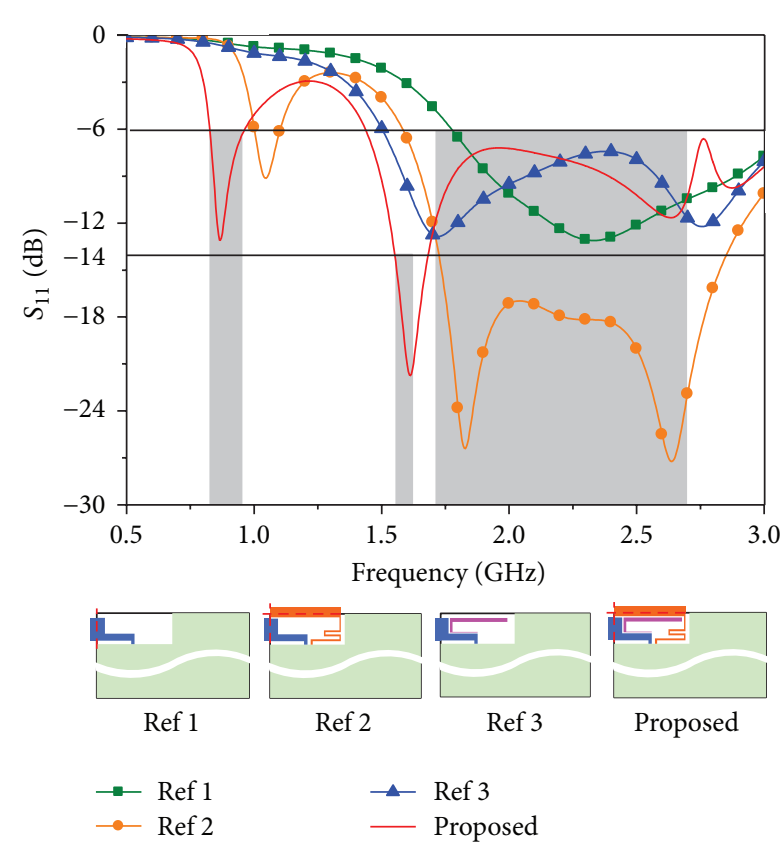

FIGURE 4: The comparison between the simulated reflection coefficient and reflection coefficient of the referenced antennas (Ref 1 contains feeding strip AC; Ref 2 contains feeding strip AC and shorted strip BF; Ref 3 contains feeding strip AC and U-shaped coupling parasitic strip DE).

point $B$ is an important parameter of the effect on coupling, so the simulated $S_{11}$ result through the analysis of distance $d$ is shown in Figure 5. The simulated results in the figure are obtained only by changing the spacing $d(1 \mathrm{~mm}-5 \mathrm{~mm})$, other dimensional parameters consistent with Figure 1. From Figure 5, the changes of the upper bands and lower bands can 


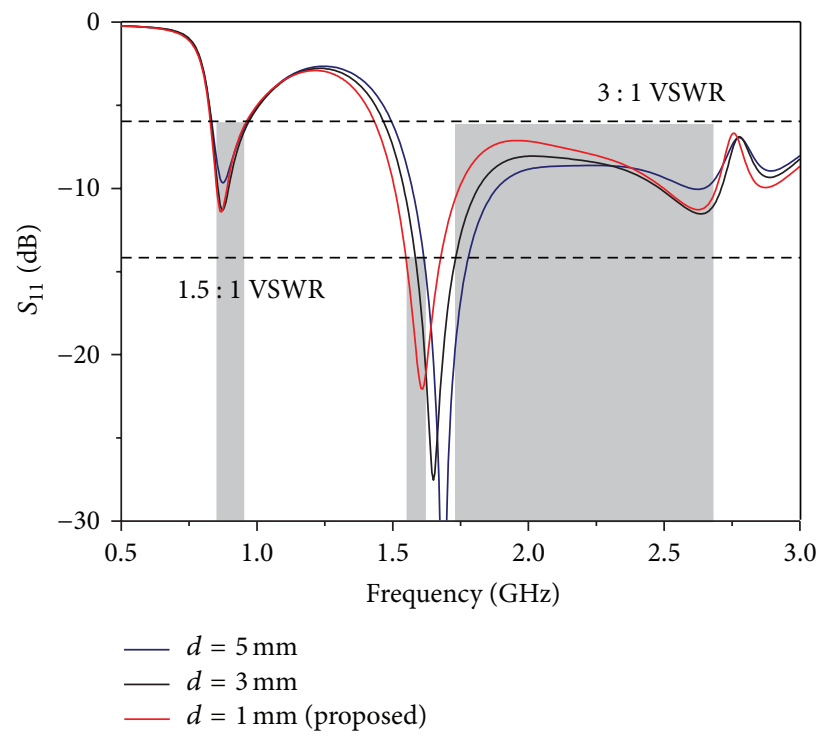

FIGURE 5: The influence of the distance $d$ (between the feed point A and shorted point B) on the simulation $S_{11}$ result.

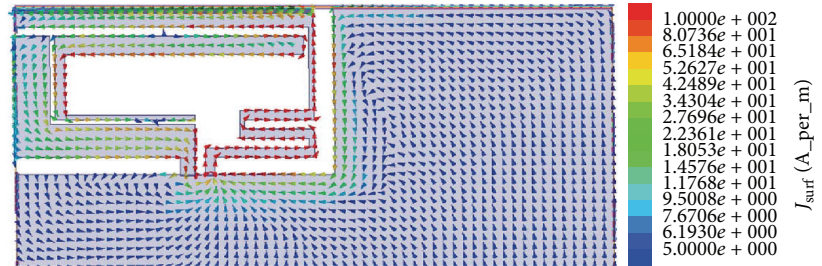

(a)

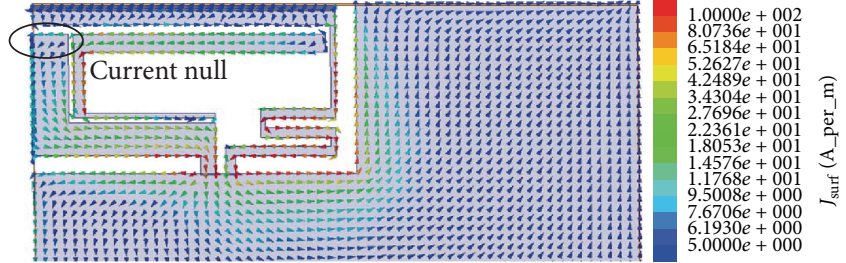

(b)

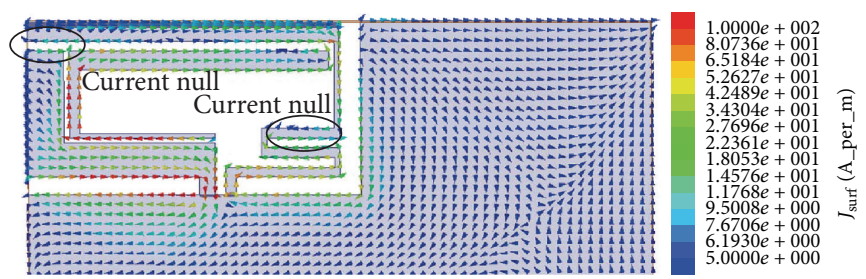

(c)

Figure 6: The simulation current distribution of the antenna: (a) $860 \mathrm{MHz}$; (b) $1620 \mathrm{MHz}$; (c) $2620 \mathrm{MHz}$.

be very clearly seen. And it also can be found that the greatest impact appeared on the $0.5 \lambda$ mode, that is, the cover bands of GNSS. Only when $d=1$ can the antenna cover GNSS bands perfectly.

Figure 6 shows the simulated current distribution of the antenna. The path length of current for the antenna is approximately $100 \mathrm{~mm}$, and it is worth noting that, under the three resonant frequencies, the ground plane of system also can generate the excited surface current. Thus, the ground plane will have some impact on the length of impedance matching of the antenna. The first resonance mode is at $860 \mathrm{MHz}(0.25 \lambda)$. The second resonance mode is at $1620 \mathrm{MHz}$ $(0.5 \lambda)$. And a current null point can be seen in Figure $6(\mathrm{~b})$. The third resonance mode is at $2620 \mathrm{MHz}(1 \lambda)$ and the two current null points are shown in Figure 6(c).
Figure 7 shows the measured radiation patterns of the antenna at three resonance frequencies, that is, $860 \mathrm{MHz}$, $1620 \mathrm{MHz}$, and $2620 \mathrm{MHz}$. It shows that the antenna has excellent omnidirectivity in the three bands, that is, lower band, GNSS band, and upper band. But at the higher frequency $2620 \mathrm{MHz}$, radiation pattern is slightly worse, which is mainly caused by the similar sizes of the working bandwidth and the ground plane. In fact, the ground plane of phone system also is an effective radiator which has a greater impact on the radiation pattern of the built-in cell phone antenna.

Figure 8 shows the measured gain and the radiation efficiency of antenna. In lower band, the gain of antenna varies from 1.88 to $4.58 \mathrm{dBi}$ and the radiation efficiency changes from $48 \%$ to $61 \%$. In the GNSS band, the gain varies from 4.2 to $4.8 \mathrm{dBi}$ and the radiation efficiency ranges within 


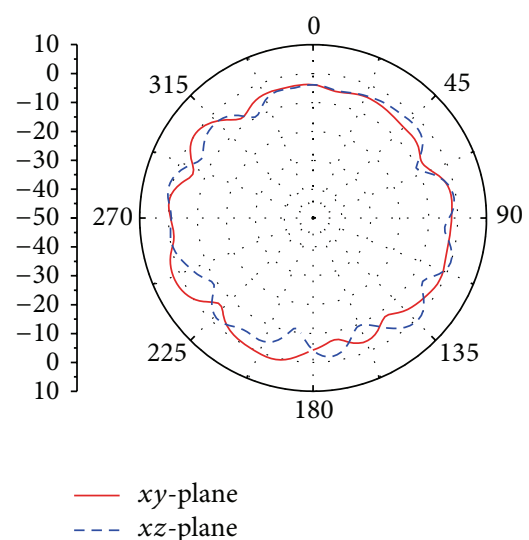

(a)

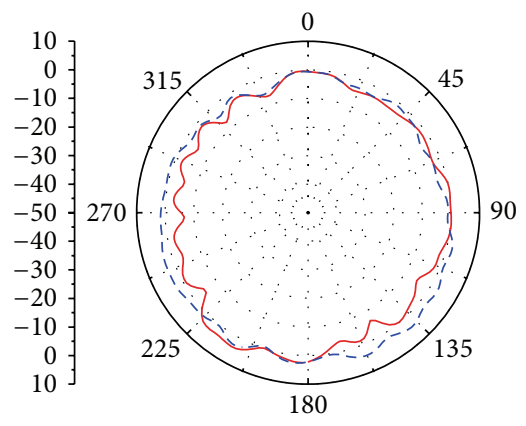

- $x y$-plane
$--x z$-plane

(b)

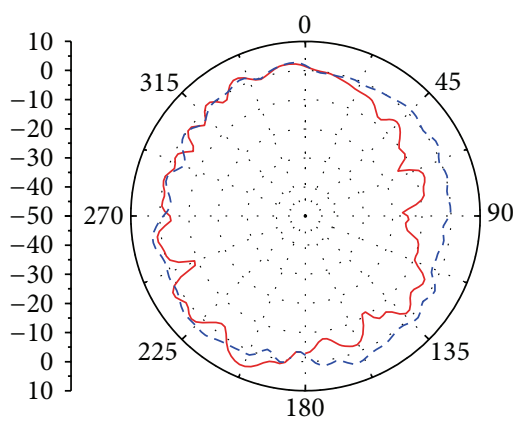

$-x y$-plane

(c)

FIgURe 7: Measured two-dimensional radiation patterns for the proposed antenna at (a) $860 \mathrm{MHz}$; (b) $1620 \mathrm{MHz}$; (c) $2620 \mathrm{MHz}$.

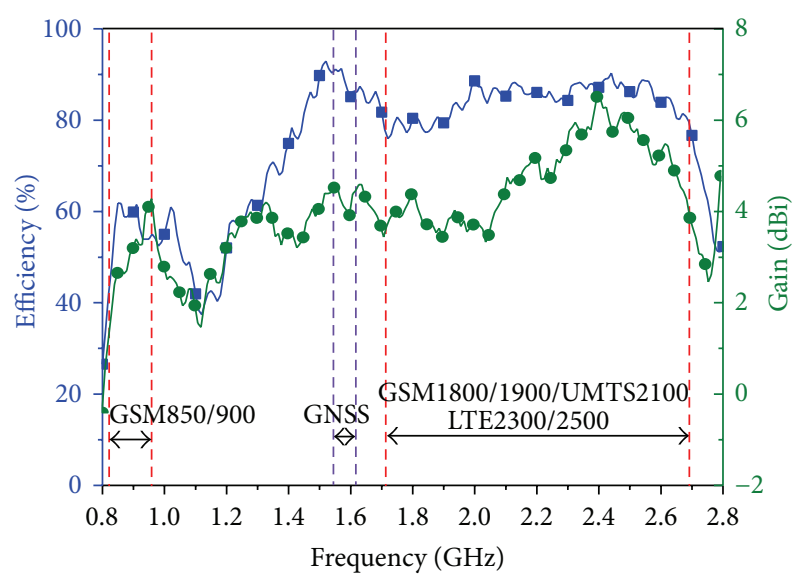

FIgURE 8: The measured gain and efficiency of antenna.

about $85 \%-91 \%$. In the upper band, the gain varies from 3.68 to $6.95 \mathrm{dBi}$ and the radiation efficiency ranges from $77 \%$ to $90 \%$. The measured radiation characteristics suggest that the proposed antenna is suitable in practical mobile communication.

Finally, because the other electronic components of the phone may affect the performance of the antenna, a universal serial bus (USB) and a microphone have been chosen to load on the additional ground plane (Figure 9). Usually, the two elements are most likely to affect the performance of antenna. First, for usual layout of the mobile phone, the two elements are very close to the antenna. Secondly, the two elements contain more metallic materials. The comparison of the measured $S_{11}$ results between this antenna and the Ref 4 antenna (loading USB and microphone) was shown in Figure 10. It can be seen that the electronic components have little effect on the performance of the antenna; that is, this antenna has rather good robustness.

\section{Conclusion}

A multiband printed loop mobile phone antenna for GNSS application is presented, which occupies a small volume of

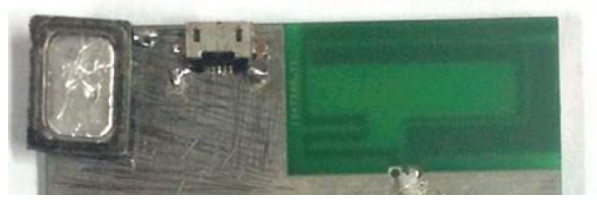

Figure 9: Photograph of loading USB and microphone on this antenna.

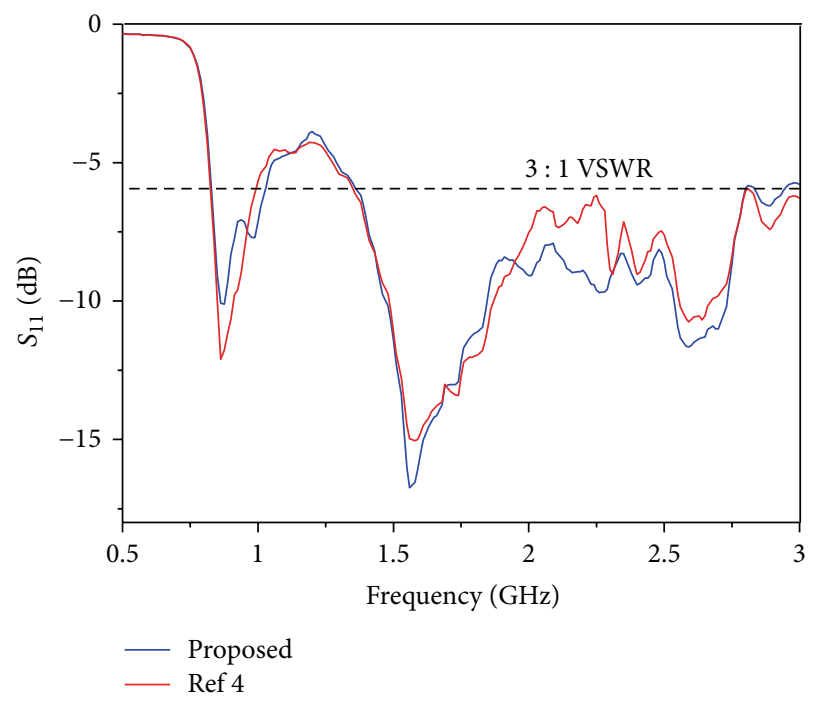

FIGURE 10: Measured $S_{11}$ result of the proposed antenna and Ref 4 (Ref 4 antenna is the proposed antenna loading of USB and the microphone).

$18 \times 32 \times 3 \mathrm{~mm}^{3}$ and has two bands of $821 \mathrm{MHz}-1012 \mathrm{MHz}$ and $1375 \mathrm{MHz}-2937 \mathrm{MHz}$. The antenna covers LTE/WWAN bands (VSWR $<3$ ) and GNSS band (VSWR $<1.5$ ). The measured results including the return loss, the radiation pattern, the antenna radiation efficiency, and gain are in line with practical application. In addition, the redundant design of multinavigation system is quite favorable for the elimination of errors or shadow area caused by single navigation system. Therefore, the multiband printed loop mobile 
phone antenna for LTE/WWAN/GNSS application has a considerable competitiveness in practical applications.

\section{Conflict of Interests}

The authors declare that there is no conflict of interests regarding the publication of this paper.

\section{Acknowledgments}

This research was supported by the Fund of the National Natural Science Foundation of China under Grant nos. 11172285 and 11472259 and Zhejiang Provincial Natural Science Foundation of China under Grant no. LR13A020002. The authors would like to express their sincere appreciation to their support.

\section{References}

[1] Z. X. Liang, Y. X. Li, and Y. L. Long, "Multiband monopole mobile phone antenna with circular polarization for GNSS application," IEEE Transactions on Antennas and Propagation, vol. 62, no. 4, pp. 1910-1917, 2014.

[2] Y.-L. Ban, C.-L. Liu, J. L.-W. Li, and R. Li, "Small-size wideband monopole with distributed inductive strip for sevenband WWAN/LTE mobile phone," IEEE Antennas and Wireless Propagation Letters, vol. 12, pp. 7-10, 2013.

[3] K.-L. Wong and S.-N. Hsu, "Small-size two-branch monopole antenna with integrated wideband matching network for LTE tablet computer," Microwave and Optical Technology Letters, vol. 57, no. 2, pp. 507-513, 2015.

[4] J. Ma, Y. Z. Yin, J. L. Guo, and Y. H. Huang, "Miniature printed octaband monopole antenna for mobile phones," IEEE Antennas and Wireless Propagation Letters, vol. 9, pp. 1033-1036, 2010.

[5] J.-H. Chen, Y.-L. Ban, and L.-J. Ying, "Compact PIFA using capacitive coupled-fed for LTE/GSM/UMTS WWAN operation in the mobile application," in Proceedings of the Cross Strait Quad-Regional Radio Science and Wireless Technology Conference (CSQRWC '11), pp. 414-417, IEEE, Harbin, China, July 2011.

[6] R. Zhang, Y. Liu, H. Kim, and H. Kim, "PIFA using seriesresonant feed structure for wide-band operations," Electronics Letters, vol. 51, no. 8, pp. 606-608, 2015.

[7] K.-L. Wong and M.-T. Chen, "Very-low-profile dual-wideband loop antenna for LTE tablet computer," Microwave and Optical Technology Letters, vol. 57, no. 1, pp. 141-146, 2015.

[8] Y. Li, Z. J. Zhang, J. F. Zheng, Z. H. Feng, and M. F. Iskander, "A compact hepta-band loop-inverted $\mathrm{F}$ reconfigurable antenna for mobile phone," IEEE Transactions on Antennas and Propagation, vol. 60, no. 1, pp. 389-392, 2012.

[9] K.-L. Wong and C.-H. Huang, "Printed loop antenna with a perpendicular feed for penta-band mobile phone application," IEEE Transactions on Antennas and Propagation, vol. 56, no. 7, pp. 2138-2141, 2008.

[10] Y.-W. Chi and K.-L. Wong, "Printed dual-band loop antenna for mobile phone application," in Proceedings of the IEEE Antennas and Propagation Society International Symposium, pp. 35763579, June 2007.

[11] Y.-W. Chi and K.-L. Wong, "Quarter-wavelength printed loop antenna with an internal printed matching circuit for
GSM/DCS/PCS/UMTS operation in the mobile phone," IEEE Transactions on Antennas and Propagation, vol. 57, no. 9, pp. 2541-2547, 2009. 


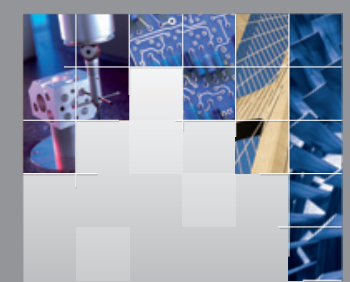

\section{Enfincering}
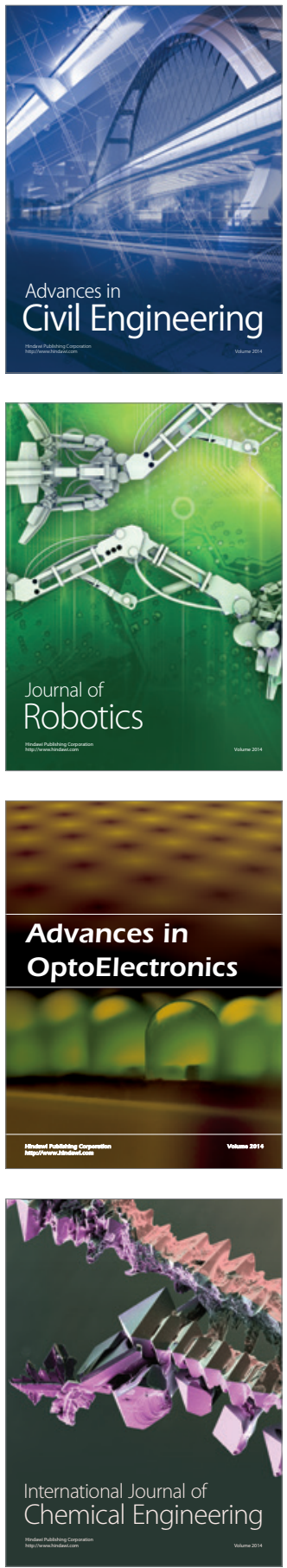

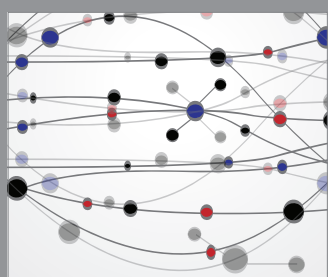

The Scientific World Journal

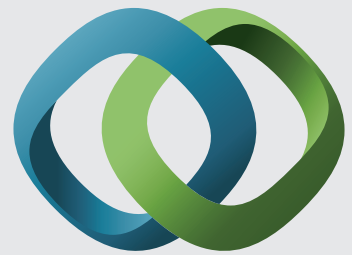

\section{Hindawi}

Submit your manuscripts at

http://www.hindawi.com
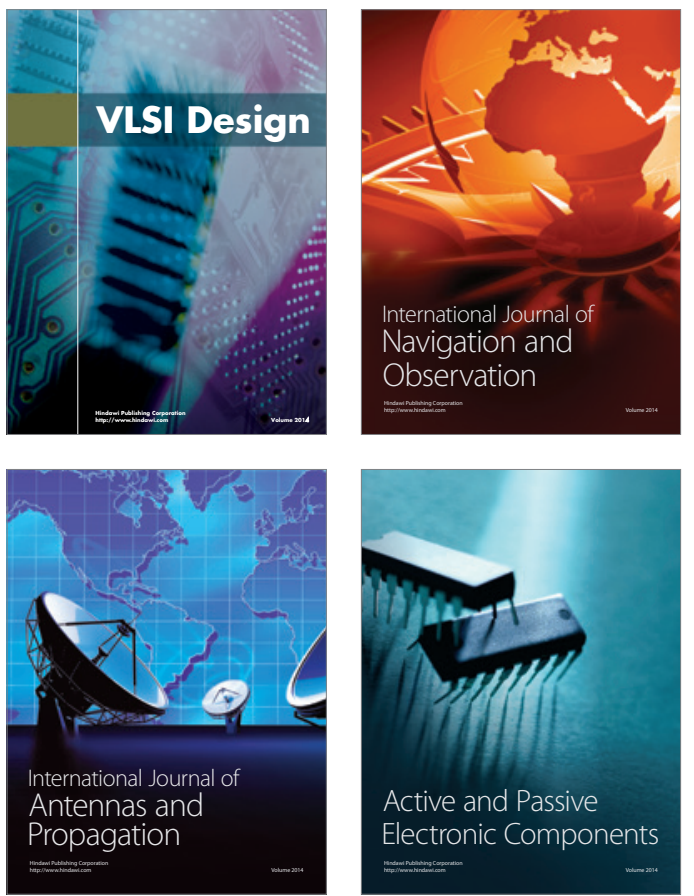
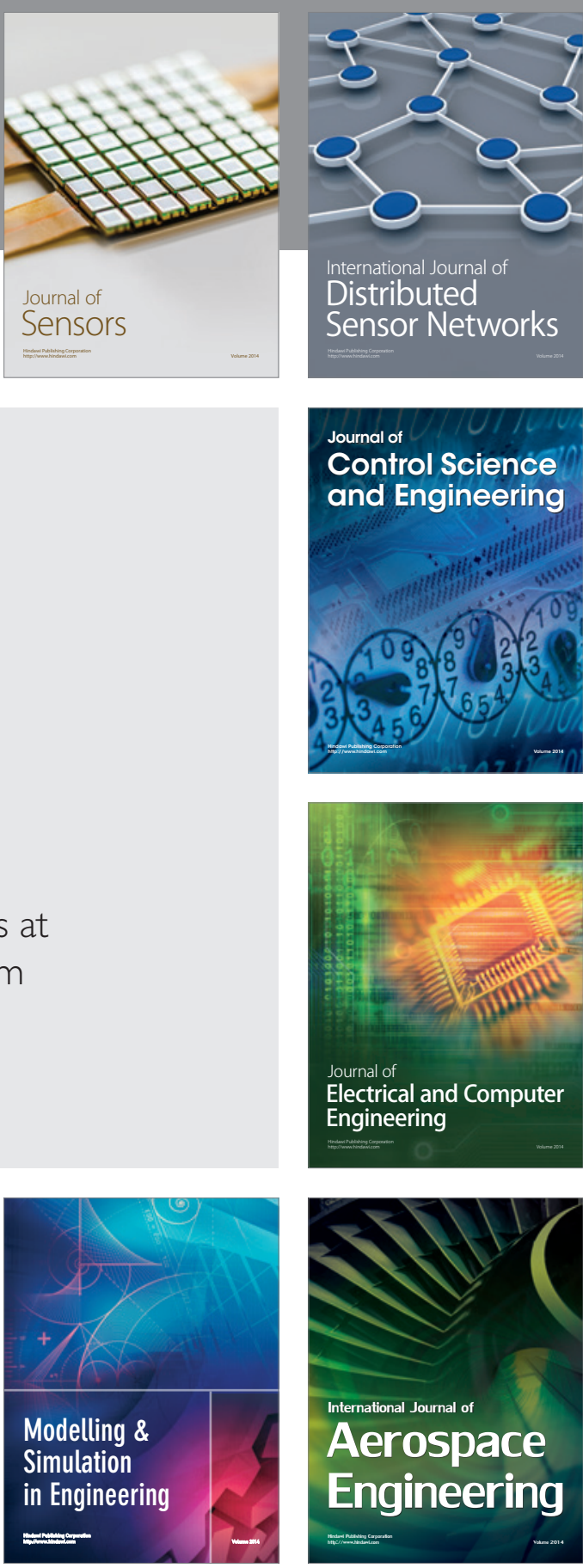

International Journal of

Distributed

Sensor Networks

Journal of

Control Science

and Engineering
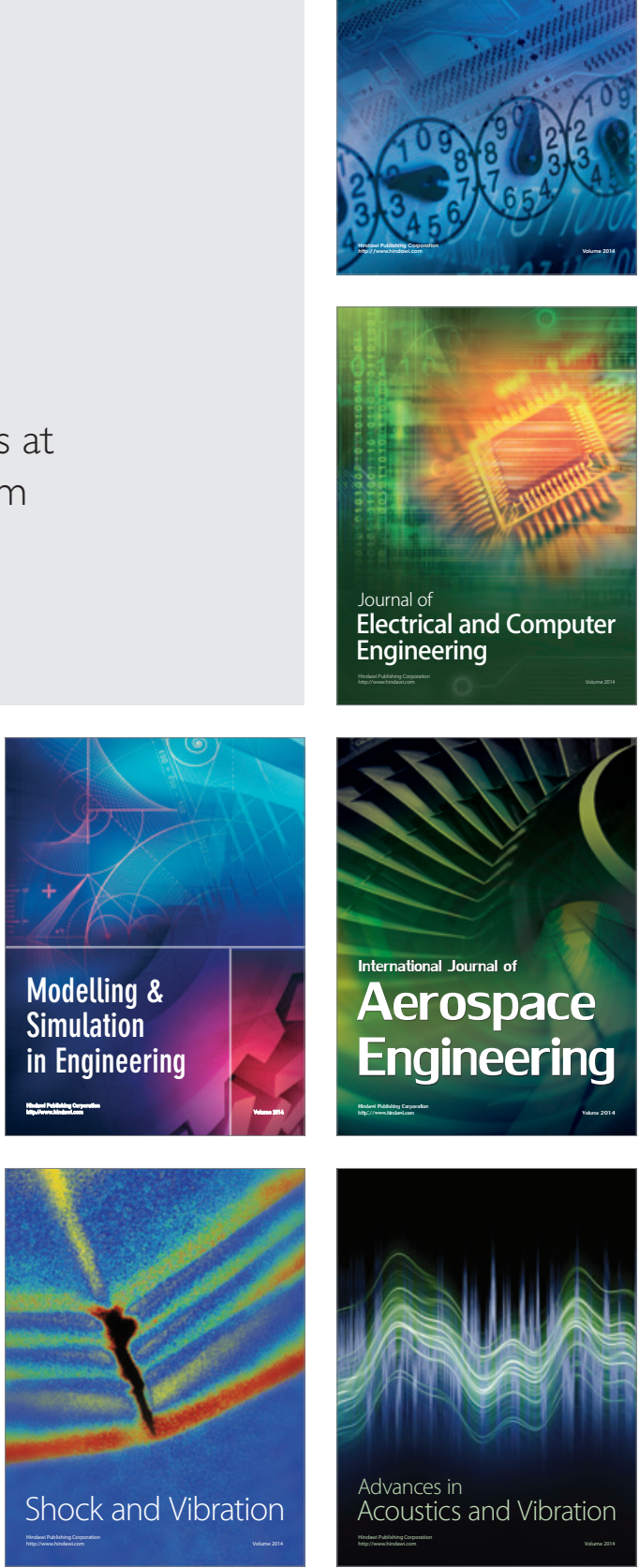